\title{
3 \\ Relationships Between Gatekeepers and Researchers: The Experience of Conducting Evaluations into Parenting Programmes in Community and Penal Settings
}

\author{
Julie T. Davies and Eleanor Peters
}

\section{Introduction}

The idea of reflexivity in research and how biographies intersect with the field is one which has been discussed by various authors in a number of settings (Finlay 2002; O'Reilly 2012). Although we address some of these issues as critical criminologists ${ }^{1}$ (Carrington and Hogg 2008), the chapter will focus on 'social critique' (Finlay 2002) in terms of the power imbalance between researcher and respondents, and the dynamics involved between the researcher and the professionals, such as social workers and criminal justice professionals, who act as gatekeepers. In a critical research approach, issues of power and powerlessness are paramount if we are to be reflexive in our research - critically analysing power, personalities, politics and marginalisation.

This chapter draws on two research projects into parenting programmes provided by a voluntary organisation in a city in the North of England. The organisation is a charity which delivers a number of interventions within the social care setting and the work with families in conflict with the law is just one part of their remit. The community parenting classes were provided to parents who were experiencing severe problems with their child's behaviour, either involvement in crime and antisocial behaviour and/or truancy. The objective was to improve parents' relationships with their children, boost confidence in their parenting skills and provide specific guidance in dealing with issues associated with problematic behaviours. The organisation's work with incarcerated fathers grew from work in the community providing parenting classes and with some adaptions this work was introduced in a local prison. The objective of the work in the prison was to not only provide 
fathers with parenting skills, but also provide a link for these fathers while incarcerated with their children by holding family visit days. These included specific activities that permitted more freedom of association, allowing parents to fully engage with their children. The research was conducted in order to evaluate the success of the projects, and this involved 52 semistructured interviews with parents, approximately 80 hours of observation during parenting classes in the prison and community, in court, during family visit days in the prison and over an activity weekend for parents and their children.

This chapter is specifically concerned with the gatekeeper-researcher relationship arising from our research into parenting programmes in the community and a penal setting. Gatekeepers are an integral part of the process of gaining access to conduct research and the researcher needs to develop a relationship with the gatekeeper in order to gain access. Gatekeepers are individuals who can introduce the researcher to the field, either an organisation or a group of people, or both. The process of gaining and sustaining entry to institutions and to groups or individuals is often a problematic area for researchers, and these difficulties are exacerbated if the research population is deemed to be vulnerable. Although vulnerability is a fluid and poorly defined category, it usually includes children, people who have been abused, people with communication impairments and those who are incarcerated, many of whom are likely to be of interest to criminologists. For example, access to the prison estate in particular is notoriously problematic, 'secret places' that are shut-off to all but those who reside at Her Majesty's pleasure or those who 'hold the keys' (King and Liebling 2008, 431). However, access to so-called vulnerable populations can be difficult in a number of settings (Scourfield 2012). The vulnerability of the research participants in this study stemmed from their involvement in the criminal justice system. The fathers in prison were obviously vulnerable due to their incarceration; the mothers in the community parenting classes were also vulnerable through issues such as alcohol and drug addiction, mental health issues, domestic violence and poverty.

\section{Vulnerable, 'hard-to-reach' populations and research ethics}

There is a tradition in social science research of using gatekeepers in ethnographic work, for example, the archetypal 'Doc' in Street Corner Society (Whyte 1955), and although this role has been analysed to some extent in ethnographies of gangs (e.g. Armstrong and Harris 1991), the role of gatekeepers in social research conducted within organisations has received less attention. There has been some recent consideration of issues of access and gatekeeping in social research and this is particularly the case when researchers want to access people who are deemed to be vulnerable, which is where formal research ethics has its part. 